\title{
Issues in medical assessment of fitness to dive review
}

\author{
Neal William Pollock
}

Department of Kinesiology, Faculty of Medicine, Université Laval, Quebec, Canada

Krzyżak and Korzeniewski [1] are commended for their effort in developing this review. While much of the content provides useful reference, some clarifications are warranted.

The primary concern regards overly broad statements regarding standards of practice. Most notably, it is not true that all recreational candidates are required to be medically evaluated prior to diving. The authors refer to the recreational diving medical screening system that is widely used internationally [2]. The participant questionnaire allows individuals to forego medical assessment if no issues are flagged. The product does not need to be "analysed by a diving instructor" beyond recognizing that "yes" has been entered against any of 10 questions. It is not expected that instructors are experts in diving medicine, nor that they will make medical decisions. The system depends upon honest and informed answers by participants, and unrecognised medical conditions might be missed, but widespread problems have not been identified.

The statement that insulin-dependent diabetes mellitus is an absolute contraindication to diving is similarly overstated. This position is held by some, but certainly not by all medical professionals. Guidelines for recreational diving with diabetes are well established $[3,4]$ and widely used internationally.

There are additional misconceptions that have crept into the paper. It is probably more myth than reality that "a vast majority of scuba divers were all young and physically fit." While the age of divers is increasing, this probably reflects a combination of long diving lifetimes and a drop in youth recruitment. There have long been participants with moderate, low, and sometimes very low physical fitness. This does not discount the importance of reasonable fitness, but it can help with perspective. The idea that divers should be able to work at an intensity of 13 metabolic equivalents (requiring an oxygen consumption rate of $45 \mathrm{~mL} \mathrm{O} / \mathrm{kg}$ body mass/minute) has often been stated, but it does not realistically reflect the minimum physical fitness level, and generally not even the mean fitness level, of recreational divers [5].

The comment that formal restrictions are more relaxed now and people fail to get training prior to participation is probably also not valid. Recognition of the need for "certification" is increasingly entrenched, and this obligation affects buying or renting diving equipment, buying breathing gas, and participating in almost any organised diving activity.

The statement that drysuit diving "protects the middle ear from flooding" is not accurate. Drysuits seal at the neck, and both wetsuits and drysuits rely on wet hoods that expose the outer ear to water to eliminate external ear squeeze issues. If the eardrum does rupture, water will enter the middle ear and transient caloric vertigo can be expected (with symptoms resolving fairly rapidly as the temperature difference within the two ears wanes). The comments on dental health are also somewhat unclear. Poor dentistry probably creates a greater risk for trapped gas and susceptibility to squeezes than the presence of caries, which by their nature are open to the environment. Finally, it is unclear that scuba diving enhances air swallowing under any normal conditions, making the comments associated with this surprising.

\section{REFERENCES}

1. Krzyżak J, Korzeniewski K. Medical assessment of fitness to dive. Part I. Int Marit Health. 2021; 72(1): 36-45, doi: 10.5603/ MH.2021.0005, indexed in Pubmed: 33829471.

2. Recreational Diving Medical Screening System. International Diver Medical Screen Committee. 2020. https://www.uhms.org/resources/recreational-diving-medical-screening-system.html (Accessed: 29 January 2021).

3. Pollock NW, Uguccioni DM. Dear GdeL. Diabetes and recreational diving: guidelines for the future. Diving Hyperb Med. 2006; 36(1): 29-34.

4. Jendle JH, Adolfsson P, Pollock NW. Recreational diving in persons with type 1 and type 2 diabetes: Advancing capabilities and recommendations. Diving Hyperb Med. 2020; 50(2): 135-143, doi: 10.28920/dhm50.2.135-143, indexed in Pubmed: 32557415.

5. Pollock NW. Aerobic fitness and underwater diving. Diving Hyperb Med. 2007; 37(3): 118-124.

Neal W. Pollock, PhD, Associate Professor, Department of Kinesiology, Faculty of Medicine, Université Laval, PEPS, 2300, rue de la Terrasse, G1V OA6 Quebec,

Canada, tel: 418-656-2131, ext. 3842, e-mail: neal.pollock@kin.ulaval.ca

This article is available in open access under Creative Common Attribution-Non-Commercial-No Derivatives 4.0 International (CC BY-NC-ND 4.0) license, allowing to download articles and share them with others as long as they credit the authors and the publisher, but without permission to change them in any way or use them commercially. 